\title{
Acquired synechia of the tongue to the mouth floor
}

\author{
Buyanbileg Sodnom-Ish, Truc Thi Hoang Nguyen, Mi Young Eo, Yun Ju Cho, Soung Min Kim, Jong Ho Lee \\ Department of Oral and Maxillofacial Surgery, Dental Research Institute, School of Dentistry, Seoul National University, Seoul, Korea
}

Abstract (J Korean Assoc Oral Maxillofac Surg 2021;47:394-397)

Sodium hydroxide or caustic soda is a corrosive agent that can cause extensive damage to the oral mucosa, lips, and tongue when ingested either accidentally or intentionally. These injuries include microstomia, shallow vestibule, ankyloglossia, speech impairment, loss of teeth and impairment in facial expression. In the present article, we report a unique case of tongue adhesion to the mouth floor and its surgical management in a 66-year-old female patient, who had a history of caustic soda ingestion.

Key words: Caustic soda, Mouth abnormalities, Tongue synechia, Suicide, Skin transplantation

[paper submitted 2019. 9. 10 / revised 1st 2019. 11. 25, 2nd 2019. 12. 1 / accepted 2019. 12. 2]

\section{Introduction}

Sodium hydroxide or caustic soda is a corrosive agent that can produce extensive injury to the oral mucous membrane, lips, and tongue when ingested either accidentally or intentionally. The ingestion of corrosive substances often leads to significant morbidity and in severe cases may lead to mortality. It can have both acute and chronic implications, often followed by life-long sequelae. Children represent $80 \%$ of the ingestion injuries in the global population, primarily due to accidental ingestion. However, the ingestion of caustic substances in adults is typically more intentional, and frequently life-threatening ${ }^{1}$. Intentional ingestion for a purpose of suicide is more damaging compared to accidental ingestion due to the large amount of corrosive substances ingested.

Oral cavity injuries caused by caustic ingestion, including microstomia, shallow vestibule, ankyloglossia, speech impairment, loss of teeth and impairment in facial expression have been reported in the literature ${ }^{2-4}$. We present a case of scar contracture between the tongue and mouth floor with

\section{Soung Min Kim}

Department of Oral and Maxillofacial Surgery, School of Dentistry, Seoul National University, 101 Daehak-ro, Jongno-gu, Seoul 03080, Korea

TEL: +82-2-2072-0213

E-mail:smin5@snu.ac.kr

ORCID: https://orcid.org/0000-0002-6916-0489

(c) This is an open-access article distributed under the terms of the Creative Commons Attribution Non-Commercial License (http://creativecommons.org/ licenses/by-nc/4.0/), which permits unrestricted non-commercial use, distribution, and reproduction in any medium, provided the original work is properly cited.

Copyright (C) 2021 The Korean Association of Oral and Maxillofacial Surgeons. stone formation in the submandibular salivary duct. Surgical treatment of using vestibuloplasty with left anterolateral thigh split-thickness skin graft (STSG), sialolith removal, sialoductoplasty, and plate splint application was performed under general anesthesia. We report a successful treatment outcome with a long-term follow-up period of more than five years.

\section{Case Report}

A 66-year-old female patient was referred to the Department of Oral and Maxillofacial Surgery at Seoul National University Dental Hospital in 2014. Her chief complaint was pain in her tongue that had begun nine months prior. The patient reported undergoing a computed tomography (CT) scan in the past and was told that there were no special problems, although the size of her salivary glands was abnormal. She also stated that the front of her tongue had been attached to the oral floor for a long time and had been symptomless. She had a history of attempted suicide by caustic soda ingestion. Fortunately, the patient had spit out the caustic substance before swallowing it. The patient also had a past medical history of hypertension, hyperlipidemia, and sensitive nervous disorders, and was taking Neurontin and medications for blood pressure and hyperlipidemia.

Extraoral examination revealed unremarkable findings with an adequate mouth opening. Intraorally, her tongue was adhered completely to the mouth floor, with restricted tongue movement.(Fig. 1. A, 1. B) Due to chemical exposure, a scar and stenosis had formed along the borders of the tongue, 

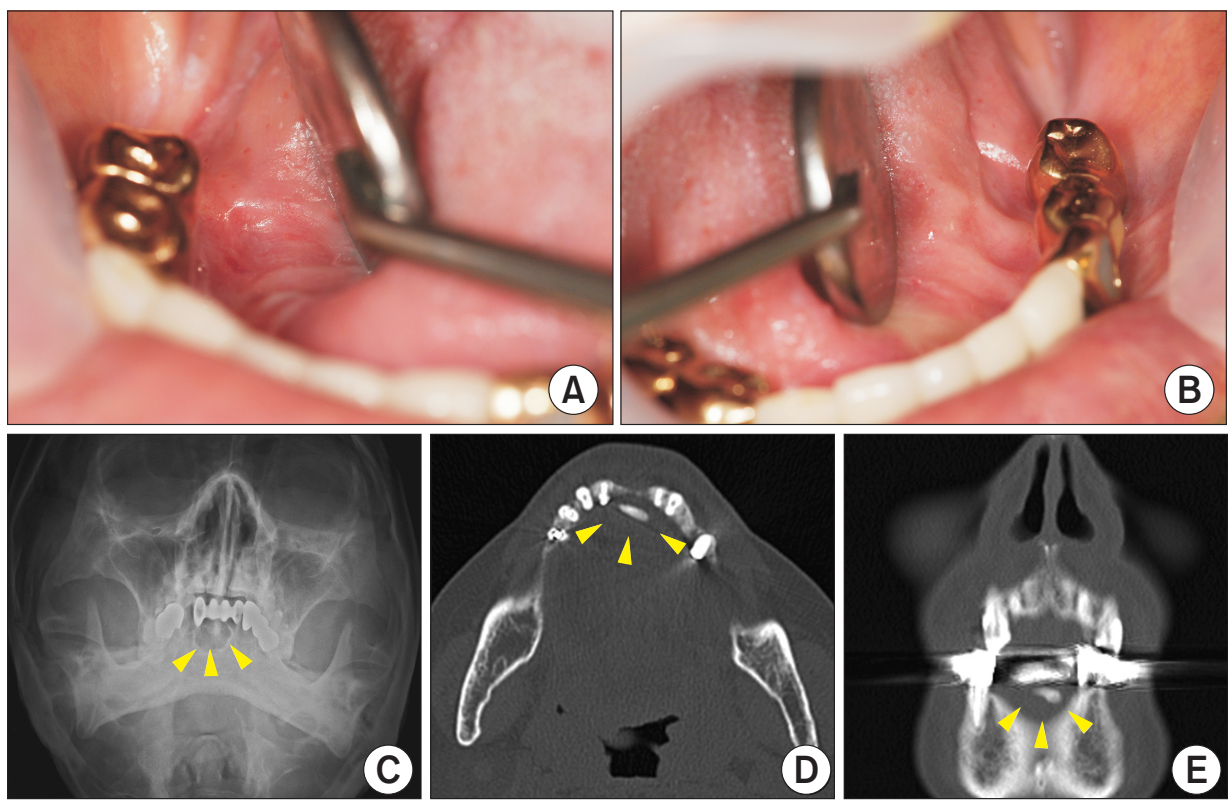

Fig. 1. A, B. A 66-year-old female patient exhibited tongue synechia that completely adhered the tongue to oral floor and restricted tongue movement. C. Preoperative Water's view showing a radiopaque sialolith in the lower incisor region (marked with arrowheads). D, E. Computed tomography (axial and coronal view) showing a highly attenuated material $8 \mathrm{~mm}$ in length at the lower part of the anterior tongue (marked with arrowheads).

Buyanbileg Sodnom-Ish et al: Acquired synechia of the tongue to the mouth floor. J Korean Assoc Oral Maxillofac Surg 2021
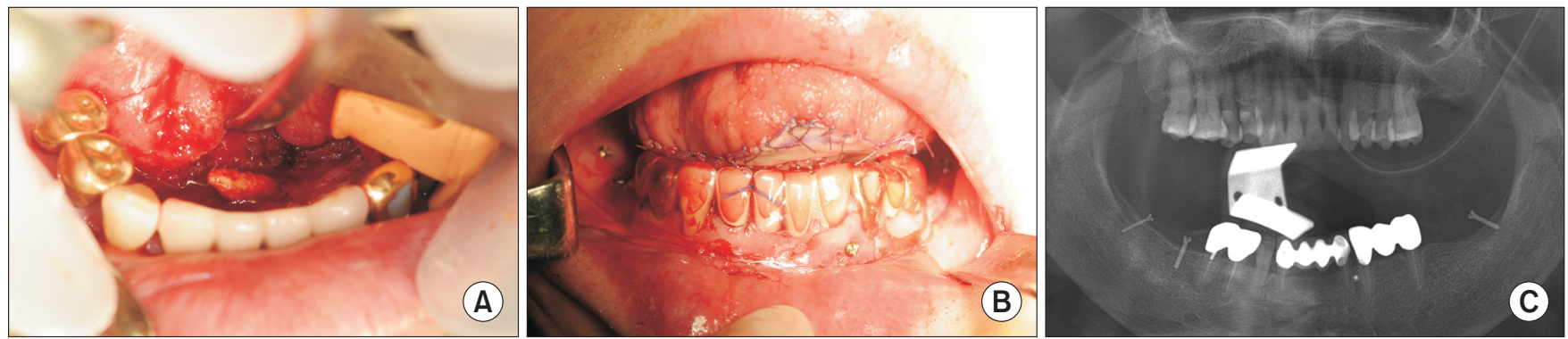

Fig. 2. A. Intra-operative view of the surgical site where the sialolith was identified and removed from the obstructed Wharton's duct. B. A barrier was made from anterolateral thigh split-thickness skin graft and sutured in place with a bolster dressing. Then a plate splint was fixated using microscrews. C. Postoperative panoramic view of the patient following the surgery.

Buyanbileg Sodnom-Ish et al: Acquired synechia of the tongue to the mouth floor. J Korean Assoc Oral Maxillofac Surg 2021

resulting in a decrease of the vestibule depth. Signs of xerostomia were observed upon inspection. Laboratory results showed a slight low platelet count of $109 \mathrm{k}$ (reference range, $130 \mathrm{k}-400 \mathrm{k}$ ) and also an erythrocyte sedimentation rate of $29 \mathrm{~mm} / \mathrm{hr}(0-20 \mathrm{~mm} / \mathrm{hr})$. But there are no suspicious disease related to these laboratory findings. Radiographic findings, including a panoramic view and; Water's view, revealed a radiopaque area in the lower incisor alveolar ridge region.(Fig. 1. C) CT (axial and coronal view) showed highly attenuated material $8 \mathrm{~mm}$ in length at the lower part of the anterior tongue.(Fig. 1. D, 1. E) Based on the clinical and radiological findings, a diagnosis of scar contracture of the tongue and sialolithiasis was made.

After careful consultation with the patient and obtaining the patient's consent, the surgical treatment was planned as follows: sialolith removal and sialoductoplasty, partial glossectomy, vestibuloplasty with STSG using an anterolateral thigh skin and plate splint application. Surgical management was essential to remove the stone and to release the tongue from the mouth's floor by making a barrier with a skin graft to prevent relapse.

The surgical procedures of sialolith removal and creation of STSG barrier between the tongue and mouth floor were carried out under general anesthesia and nasotracheal intubation. The incision for vestibuloplasty and sialolith removal was made longitudinally along the margins of the attachment between the tongue and mouth floor. The sialolith was then located and removed along with dilatation of the Wharton's duct.(Fig. 2. A) After removal of the sialolith, further vestibuloplasty of the mouth floor was carried out. To prevent any relapse of the tongue's attachment and sialolith formation, STSG from the anterolateral thigh was harvested using a dermatome. The skin graft was then placed in the operation area and sutured. A bolster dressing was attached on the skin graft to prevent displacement and fluid accumulation. Following STSG vestibuloplasty, the plate splint was placed and fixated 

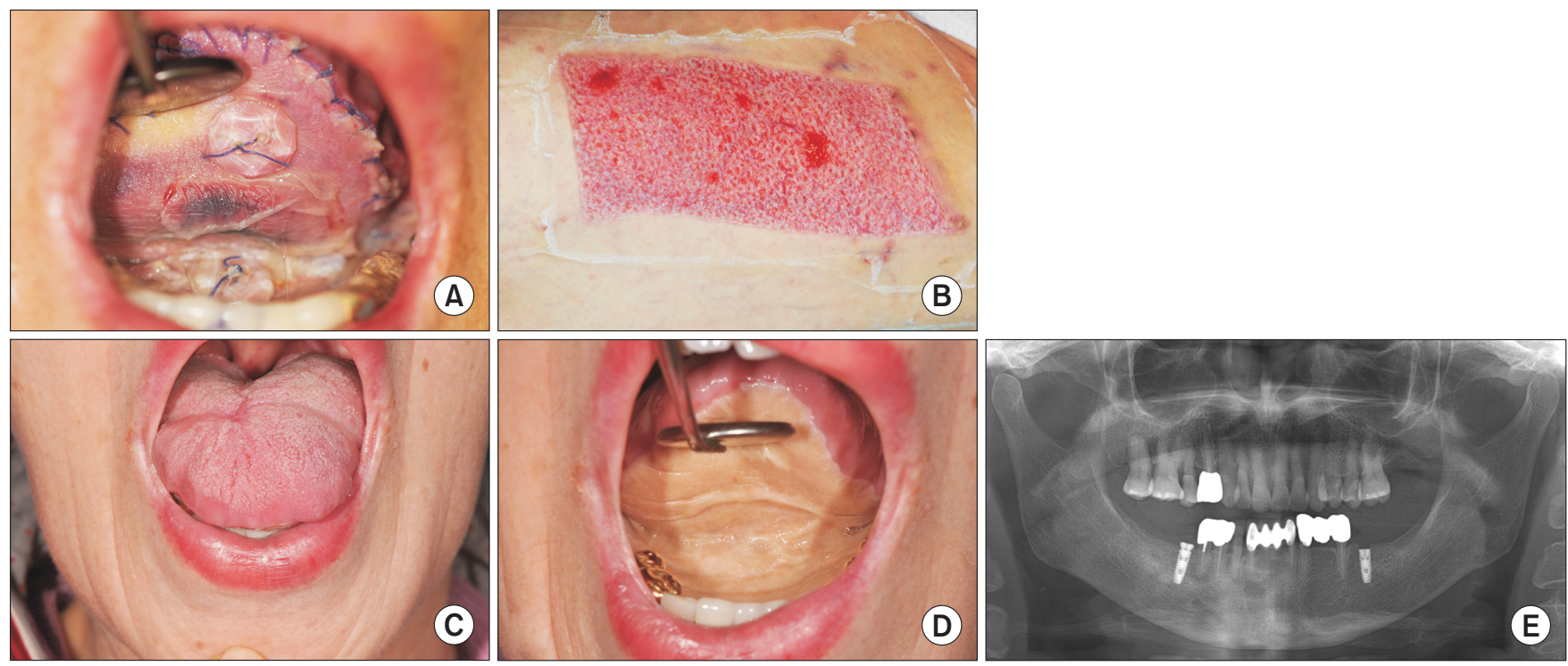

Fig. 3. A, B. The patient exhibited uneventful healing after one week and no morbidity associated with the anterolateral thigh split-thickness skin graft (STSG) donor site. C, D. Intraoral view of the patient five years after the surgical release and anterolateral thigh STSG barrier were carried out. E. A panoramic view of the patient after installation of \#36, \#46 implant fixtures.

Buyanbileg Sodnom-Ish et al: Acquired synechia of the tongue to the mouth floor. J Korean Assoc Oral Maxillofac Surg 2021

with microscrews.(Fig. 2. B, 2. C)

The patient received standard postoperative care and had regular check-ups after the surgery at five days and at one week, she exhibited uneventful healing with no morbidity and no complications associated at donor site.(Fig. 3. A, 3 . B) Two and a half weeks later, the plate splint fixated with microscrews was removed. The patient was instructed to perform regular tongue exercises and maintain proper oral hygiene. At the one-month follow-up visit, the sutures and the tongue bolster dressing were removed. Our patient received a long-term follow-up period lasting more than five years, and ideal positioning of the skin graft was achieved.(Fig. 3 . C, 3. D) Initially, the patient have not shown the satisfactory emotion due to her new adaptation situation between tongue movement and mouth floor space, but she has fully adapted to the improved speech and comfortable hygiene care. And she wanted to rehabilitate her partially edentulous state with dental implants.(Fig. 3. E)

\section{Discussion}

The age of occurrence for caustic ingestion follows a bimodal pattern. The first peak is seen in children aged from 1-5 years and, primarily includes accidental ingestions. The second peak occurs in adults 21 years of age and older. As seen in our case report, most caustic ingestions in adults are the results of suicide attempt ${ }^{5}$.
The nature of the injury caused by caustic soda ingestion is determined by several factors, such as the type of substance, the quantity, the concentration, the morphologic form of the agent, and the length of time the agent is in contact with the tissue, as well as the intent ${ }^{5,6}$. Adults with suicidal intention often consume large amounts of corrosive agents, therefore, the degree of injury is higher than that seen with accidental ingestion ${ }^{7}$. Furthermore, the liquid form of the caustic agent makes it easy to be swallowed and to reach distant sites of the gastrointestinal tract. Thus, the extent of the injury is usually found in the esophagus and stomach. Similarly, in the literature caustic soda ingestions are mostly related to injuries to the respiratory and the gastrointestinal tract. But in our present case, the injury was only restricted in the mouth floor and resulting tongue attachment to the mouth floor.

When ingested, caustic agents often produce profound and irreversible pathologic changes that often require reconstructive surgery. The most common caustic agent that induces injury is sodium hydroxide, as seen in our report. Alkalis have a more destructive effect than acids, because of their lytic effect on tissues ${ }^{7}$. The mechanism of injury of alkaline agents is their ability to combine with tissue proteins to form proteinates, and combine with fats to form soap in addition to water, resulting in liquefaction necrosis. These formed products favor the penetration of the remaining alkali into the tissue by increasing the solubility of the caustic soda. As a result, the alkali reaches deeper tissue layers, consequently producing 
lesions in the entire thickness of the organ ${ }^{8}$.

Decreased tongue mobility can have deleterious effects on oral hygiene and; erupted dentition; and may secondarily affect speech, breathing, chewing and swallowing. Another long-term effect is transformation to malignancy at the stricture site. The risk is of progression to cancer has been estimated as $10.8 \%$. Thus, it is reasonable to require lifelong follow-up in all patients with caustic soda burns ${ }^{9}$.

In the literature, little has been written about the release of tongue attachment to the mouth floor and reconstruction with STSG. The management of any long-term effects from the maxillofacial reconstructive surgeon's perspective is not definitive because of the variability of numerous factors. Therefore, surgeons should select appropriate surgical procedures and methods depending on the patient's individual situation $^{7}$. Surgical release of cicatricial tissue, skin grafting and splinting are the most common methods of treatment in oral scar contractures. We chose anterolateral thigh free flap STSG as the donor site for releasing and making a barrier for the tongue and oral floor due to the high versatility and, flexibility and low morbidity of this donor site. One disadvantage of STSG is secondary shrinkage of the skin graft, but in our case, the skin graft exhibited a long-term ideal position after more than five years follow-up.

In conclusion, a case of acquired synechia of the tongue to the mouth floor following caustic soda ingestion is presented in our report. Oral surgery was essential for releasing the tongue and creating a barrier using a skin graft. The patient experienced long-term satisfactory results after more than five years of follow-up and retained a hopeful life after suicide attempt. In cases such as these, it is essential to maintain long-term follow-up and educate the patients with oral hygiene maintenance in order to improve the quality of life especially in patients with a suicide attempt.

\section{ORCID}

Buyanbileg Sodnom-Ish, https://orcid.org/0000-0002-4239-1420

Truc Thi Hoang Nguyen, https://orcid.org/0000-0002-8667-6698

Mi Young Eo, https://orcid.org/0000-0001-7055-9924

Yun Ju Cho, https://orcid.org/0000-0002-1818-5280

Soung Min Kim, https://orcid.org/0000-0002-6916-0489

Jong Ho Lee, https://orcid.org/0000-0002-8843-545X

\section{Authors' Contributions}

B.S-I. and T.T.H.N. participated in data collection and wrote the manuscript. M.Y.E. and Y.J.C. participated in the study design and helped to draft the manuscript. S.M.K. and J.H.L. coordinated, read and approved the final manuscript.

\section{Acknowledgements}

This research was supported by Basic Science Research Program through the National Research Foundation of Korea (NRF) funded by the Ministry of Education (2017R1D1A1B04029339).

\section{Conflict of Interest}

No potential conflict of interest relevant to this article was reported.

\section{References}

1. Contini S, Scarpignato C. Caustic injury of the upper gastrointestinal tract: a comprehensive review. World J Gastroenterol 2013;19:3918-30. https://doi.org/10.3748/wjg.v19.i25.3918

2. Varkey P, Tan NC, Chen HC. Corrosive injury of oral cavity--a rare presentation. J Plast Reconstr Aesthet Surg 2006;59:1110-3. https:// doi.org/10.1016/j.bjps.2006.03.069

3. Gupta SK, Rana AS, Gupta D, Jain G, Kalra P. Unusual presentation of caustic ingestion and its surgical treatment: a case report. J Maxillofac Oral Surg 2011;10:74-6. https://doi.org/10.1007/ s12663-010-0092-x

4. Chidzonga MM. Microstomia following caustic soda ingestion: report of a case. J Maxillofac Oral Surg 2021;20:230-3. https://doi. org/10.1007/s12663-019-01247-4

5. Lupa M, Magne J, Guarisco JL, Amedee R. Update on the diagnosis and treatment of caustic ingestion. Ochsner J 2009;9:54-9.

6. Ramasamy K, Gumaste VV. Corrosive ingestion in adults. J Clin Gastroenterol 2003;37:119-24. https://doi.org/10.1097/00004836200308000-00005

7. Ichioka S, Nakatsuka T, Minegishi Y, Asato H, Takato T, Harii K. Microsurgical reconstruction for caustic injuries of the oral cavity and esophagus. J Reconstr Microsurg 2000;16:357-61. https://doi. org $/ 10.1055 / \mathrm{s}-2000-7345$

8. Mamede RC, de Mello Filho FV. Ingestion of caustic substances and its complications. Sao Paulo Med J 2001;119:10-5. https://doi. org/10.1590/s1516-31802001000100004

9. Ryan F, Witherow H, Mirza J, Ayliffe P. The oral implications of caustic soda ingestion in children. Oral Surg Oral Med Oral Pathol Oral Radiol Endod 2006;101:29-34. https://doi.org/10.1016/ j.tripleo.2005.04.025

How to cite this article: Sodnom-Ish B, Nguyen TTH, Eo MY,

Cho YJ, Kim SM, Lee JH. Acquired synechia of the tongue to the mouth floor. J Korean Assoc Oral Maxillofac Surg 2021;47:394-

397. https://doi.org/10.5125/jkaoms.2021.47.5.394 